\title{
TITLE:
}

\section{Additional Report of Halophilous Collembola of Japan}

$\operatorname{AUTHOR}(S)$ :

Yoshii, Ryozo; Sawada, Kohei

\section{CITATION:}

Yoshii, Ryozo ...[et al]. Additional Report of Halophilous Collembola of Japan.

PUBLICATIONS OF THE SETO MARINE BIOLOGICAL LABORATORY 1997, 38(1-2): 13-20

ISSUE DATE:

1997-12-25

URL:

http://hdl.handle.net/2433/176276

RIGHT: 


\title{
Additional Report of Halophilous Collembola of Japan
}

\author{
Ryozo YoshiI ${ }^{1}$ and Konei SAWAda ${ }^{2}$ \\ 1 637-5 Shokokuji Monzencho, Kyoto, Japan \\ 2 15-10 Tennohcho, Takatsuki, Osaka-fu, Japan
}

\begin{abstract}
Halophilous Collembola of Japan are reported including the description of Halofriesea kuroshio n.g. n.sp. and Heterosminthurus kiianns n. sp.
\end{abstract}

Key words: halophilous, Collembola, new genus, new species, Japan

\section{Introduction}

This is to reconfirm the report of the second author, regarding the halophilous Collembola nominated in his work in Nishimura, S. (Ed.): The Guide to Sea Shore Animals of Japan. vol. 2, pp. 435-444, Osaka, 1995. Species of special interest have been examined in detail. The result is an addition to the report of Yosii (1971).

\section{Hypogastrura (Ceratophysella) duplicispinosa Yosii}

Hyp. cf. duplicispinosa: Sawada 1995

This is a haloxenous species already reported from Japan, China, and Thailand.

\section{Halofriesea g.n.}

Type species: Halofriesea kuroshio sp.n.

This marine genus is separated from Friesea and Conotelsa by the presence of a protrusion on the pleural part of three thoracic segments.

\section{Halofriesea kuroshio sp.n.}

(Fig. 1)

Friesea (Conotelsa) cf. pacifica: Sawada 1995

SHIZUOKA: West coast of Izu Peninsula (6 ex., 19 VII 1993)

Body $1.5 \mathrm{~mm}$ long, slender. Colour deeply bluish black, but segmental margins and some spots are depicted. Ant./head as $8 / 10$, head being protruded forwards. Ant. ratio as 10:13:10:12. Ant. III and IV half fused dorsally. Ant. IV is with a subapical bulb, half concealed and often trilobed, together with 5-6 short, curving sensory setae. Ant. III-organ is two small bulbs inside the groove. Labrum (fig. A) is half confluent with clypeal area and not easy to identify, but when it is compared with that of $F$. sublimis and $F$. paula in Yosii 1966, it may be interpreted as $4 / 3,3,4$ or $4 / 3,5,2$. Outer max. lobe is absent. Mandible (fig. B) elongated, distal part is with a finely denticulated, subtriangular lamella. Maxilla (fig. B) also elongated, but with strong apical part and with a fine inner tooth, with an obscure lamella near by. Labium (fig. C) is with one apical papilla. Eyes $8+8$. Pao. is absent. Each segment of thorax is bearing a small protrusion on each side on pleural area near coxal basis (fig. $\mathrm{H}$ ). Abd. VI is with 3 strong spines representing a-1 and $\mathrm{p}-0$. Other body setae are all smooth and not modified. Their pattern is rather 


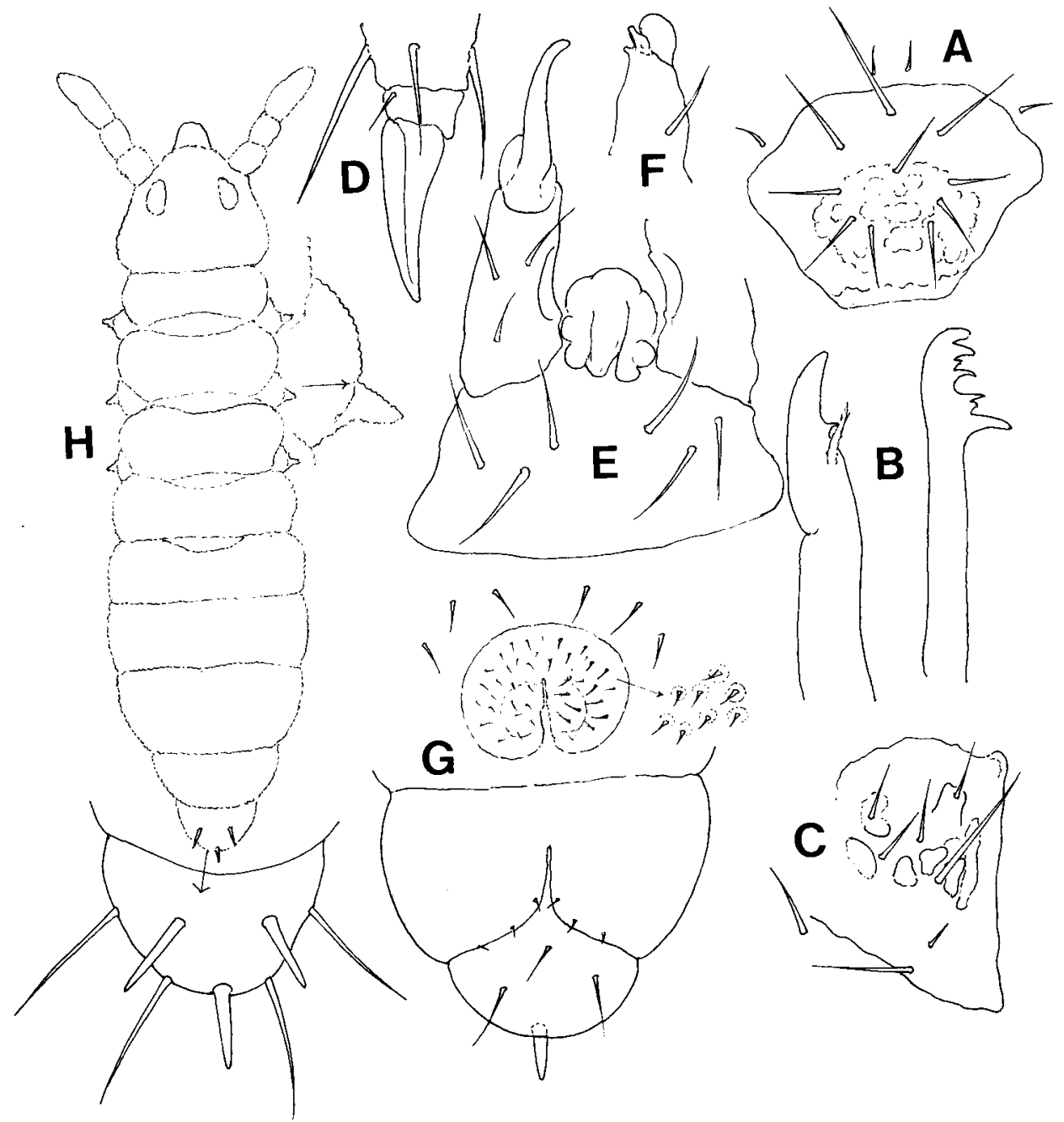

Fig. 1. Halofriesea kuroshio g.n. sp.n. A: labrum, B: mandible and maxilla, C: labium, D: unguis, E: furca and tenaculum, F: mucro (deviated form), G: abd. V, VI (ventral side), H: habitus.

polychaetotic, so that th. I is with $4+4$ setae, other setae of trunk are all asymmetric in distribution. Only one slender, long s.s. is at the position of p-2 on abd. V. Ventrally, gular median setae as 1,1 . Ventral tube with $2+2$ setae. Unguis (fig. D) is untoothed, unguiculus absent. Rami tenaculi are tridentate. Furca (fig. E) is small, m:d:mu as 10:10:8. Manubrium is half confluent with sternum, with $3+3$ setae. Dens is dorsally granulated, with 3 setae. Mucro has a broad basal swelling. Mucro itself is usually elongated and apically incurved, but sometimes reduced to a small rod (fig. F). Genital orifice (fig.G) is rounded, large and with many setulae in male and hemicircular, with fewer setae in female. Anal orifice is trilobed, median lobe has 3 setae, lateral lobe with many setae and with 3 minute setulae along the margin.

From other species of the same genus, H. kai (Chr. Bell., 1992) of Hawaii, this species may be easily separated by the presence of strong anal spines of abd. VI, which are substituted by some 7 modified setae in the cited species. The halophilous species around 
Japan belonging to Friesea and its allies may be keyed out in the following way: (* not Japanese)

1. Furca reduced, mucro vestigial or absent..... Friesea s. str. furca not reduced, mucro distinct.... 2

2. Thoracal segment with lateral protrusion..... Halofriesea g.n.....3

Thoracal segment without such..... Conotelsa.....4

3. Abd. VI with 3 strong spines.... Halofriesea. kuroshio sp. $\mathrm{n}$.

Abd VI with ca. 7 modified setae, but not spiny.... H. kai Chr. Bell, 1992*

4. Abd. VI without modification of setae.... Conotelsa acuminata Denis, 1925*

Abd. VI with 5 spines.... Conotelsa pacifica Yosii, 1958

Abd. VI with 7 spines.... Conotelsa oshoro (Uchida et Tamura, 1966)

\section{Oudemansia esakii (Kinoshita)}

Pseudachorutes esakii: Kinoshita 1932, Uchida 1951

Oudemansia esakii: Yosii 1958, Christiansen et Bellinger 1992

HONG KONG: Toro Harbour (12 ex., 29 II 1996 Sawada)

Distribution. Japan, Hawaii, Hong Kong

\section{Oudemansia coerulea Schött}

(Fig. 2)

Oudemansia coerulea: Schött, 1893

Oudemansia subcoerulea: Denis 1948, Yosii 1971, syn. nov.

Oudemansia cf. hirashimai: Sawada 1995

WAKAYAMA: Kada (6 ex., 11 V 1990); SHIZUOKA: west coast of Izu Peninsula (1 ex., 19 VII 1993)

Here I regard $O$. subcoerulea to be a junior synonym of $O$. coerulea Schött, 1893, which differs from it by more slender form of anal spines. $O$. coerulea is described from the "Tausendinseln" of Indonesia. The place is now called "Pulau Seribu" (Pulau-island, seribu-thousand), a resort island off the coast of Jakarta, where I have stayed for 2 days in 1988, only to find species with slender form of anal spines. Thus I regard the figure of Schött, to be an exaggeration or caused by the drying of the example. Besides, there are two species inquirenda, Oudemansia oceanica (Uchida, 1955) of Marcus Island is almost the same with this species, but "mandible with smooth ends, wanting any apical minute teeth" is incredible. O. hirashimai Uchida, 1965 of Okinawa is also very allied, but differing by the presence of only 5 dental setae instead of 6 .

Here, I give the full description after Indonesian examples: Body length ca. $1.2 \mathrm{~mm}$, intensely bluish black, including antennae and other extremities. There are many pale spots and stripes symmetrically arranged as in fig. A. They are along segmental margins and on fovulae, where the integment is less granulated. Ant.:head as 8:10, ratio as 10:8:6:7, distal two segments are fused dorsally. Ant. IV has trilobed apical bulb (fig. B) and some 4-5 sensory setae. Ant III-organ is two rods in a deep groove. Head has a long protruded mouth parts. Labrum is elongated (fig. C), quite the same with the other species. Mandible and maxilla (figs. D, E) are elongated, the former is with a triangular lamella on one side, minutely serrated, the latter is quite pointed. Labium is also the same with others. Eyes $8+8$, pao. is absent. Genal median setae 1,2. Thoracal sternum without setae. Unguis (fig. F) strong, with or without inner tooth. Unguiculus and tenent hair absent. Ventral 


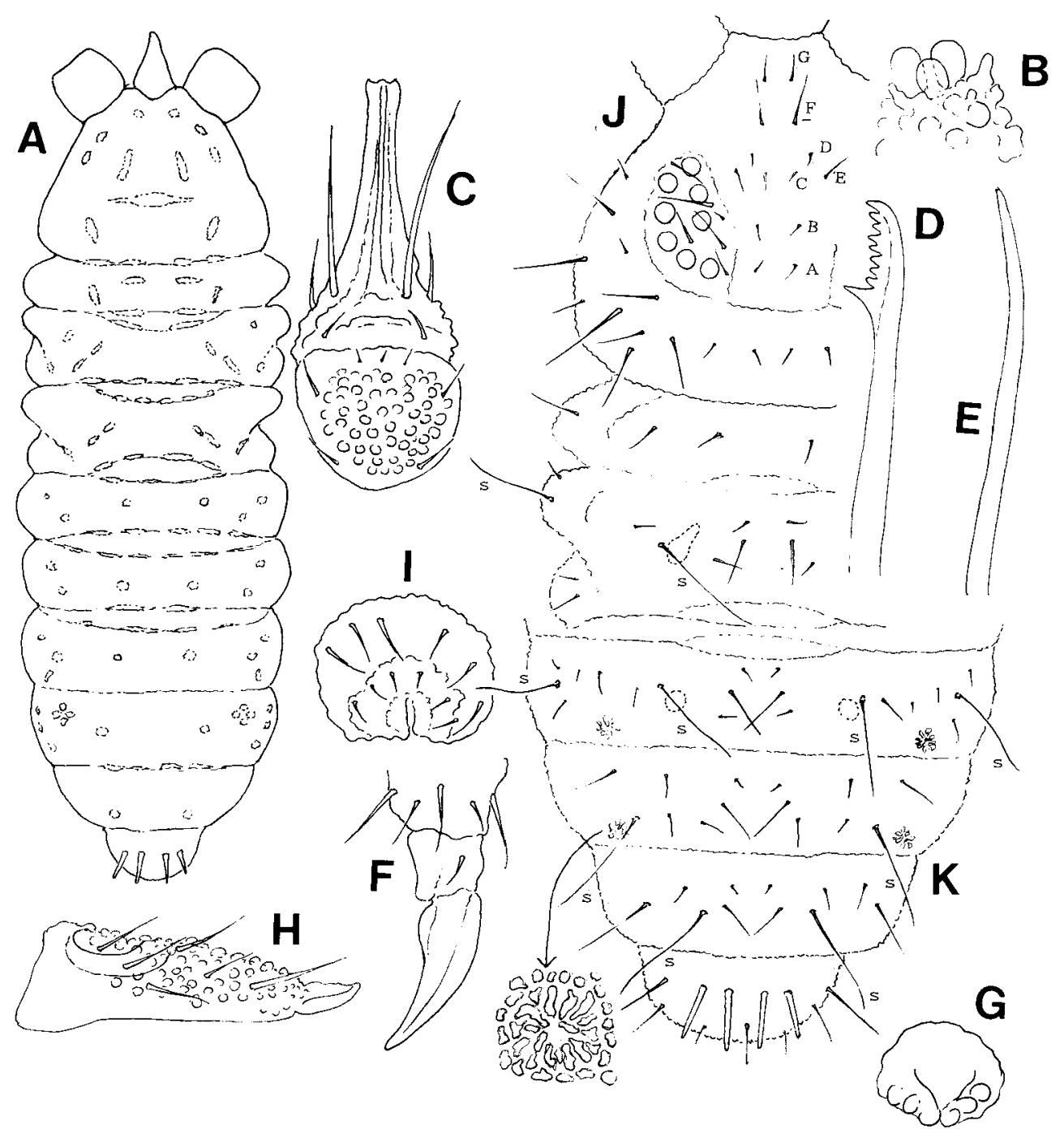

Fig. 2. Oudemansia coerulea Schött from Indonesia A: habitus, B: ant. IV, C: labrum, D: mandible, E: maxilla, F: unguis, G: tenaculum, H: dens and mucro, I: male genital orifice, J: head and th. I, II, K: abd. III, VI.

tube with $2+2$ distal setae and $2+2$ setae near the basis. Rami tenaculi (fig. $G$ ) are tridentate, corpus without seta. Furca is half fused with sternum. Dens (fig. $\mathrm{H}$ ) is granulated dorsally and with 6 setulae. Mucro is ca $2 / 5$ of dens, lightly incurving, ventrally keeled and obtuse on apex. Dorsal part is continuous with dens. Male genital orifice as in fig. I. Abd. VI is with 4 strong anal spines attached without basal papilla, representing a-1 and a-2 of abd. VI. Chaetal pattern (figs. J, K) of the head is very alike to that of Neanura, having the cephalic setae of $\mathrm{A}$ to $\mathrm{F}$ in the same position. But ocular and occipital area has more number of setae. Th. I is with $3+3$ setae, rather exceptional for Pseudachorutinae. Th. II, III have a light swelling on anterior lateral part, somewhat alike to Neanura and one of the two s.s. is located on it. Setae are in 3 rows on all segments of Th. II-Abd. IV, m-1 is larger and s.s. are more elongated and located at the 
position of $\mathrm{p}-3$. Abd. $\mathrm{V}$ has setae in two rows, p-2 is s.s., p-1, 3 are elongated.

Integument is very warty all over, heavily granulated. There exists a kind of rounded assembly of irregular granules in form of a rosette, lateral to $\mathrm{p}-3$ on all segments of Abd. I-IV.

\section{Lobella (Yuukianura) halophila (Yosii)}

(Fig. 3)

Yuukianura halophila: Yosii 1955, 1961

Lobella halophila: Sawada 1995

TOKUSIMA: Ohkamikokama (4 ex., 15 V 1993 Sawada.)

Following addition is to be given to my previous description. Labrum (fig. D) wedge-shaped, with $2+2$ setae. Mandible and maxilla as in figs. E, F. Unguis with one

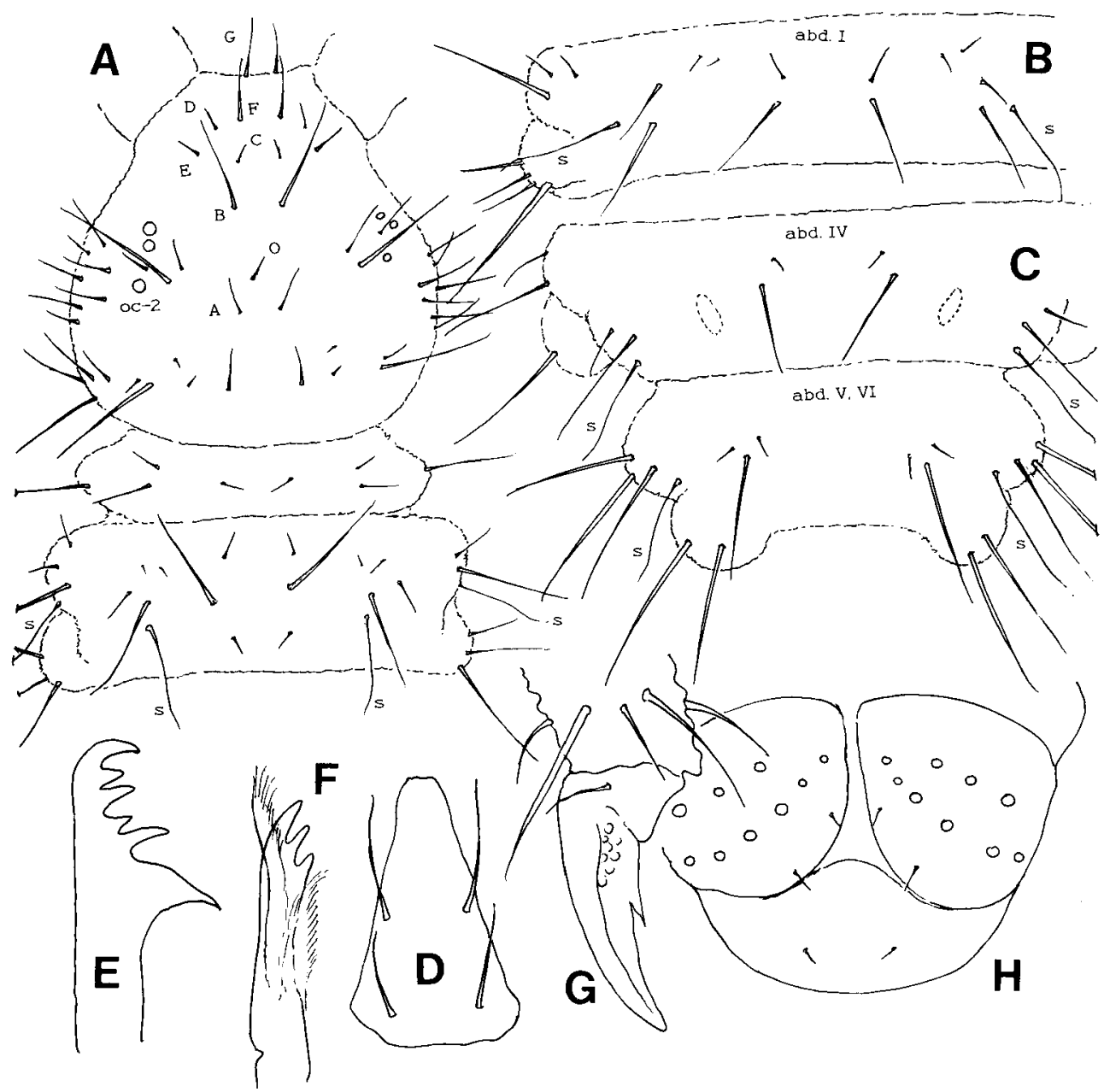

Fig. 3. Lobella (Yuukianura) halophila (Yosii) from Shikoku. A: head and th. 1, II, B: abd. I, C: abd. IV, V+VI, D: labrum, E, F: mandible and maxilla, G: unguis, H: anal orifice. 
inner tooth and basally granulated. Segmental tubercles (figs. A, B, C) are all reduced, represented by the assembly of setae dorsally, plus by the rounded swelling laterally.

In one example seta-o of the head is in one pair, but such deviation is already known in Lobella sauteri (cf. Yoshii 1994). Seta-B and oc-2 are enlarged. Setae of other parts are as:

Occ.: 1 ---ii----i + I----II + many

Th. I: 1-----2----I

Th. II, III: $1+$ I + 1---ii---s + I + 1---I $+1+$ s----I +2

Abd. I-III: $1+$ I----ii----1 $+\mathrm{I}+\mathrm{s}----2+\mathrm{I}------4$

Abd. IV: $1+\mathrm{I}-------1+\mathrm{I}+\mathrm{s}----1+\mathrm{I}-----4$ ?

Abd. V: $2+\mathrm{I}-----\mathrm{s}+\mathrm{II}+2$

On abd. IV and V, setae of dorsal group are widely apart, lateral group of abd. V are fused in a common hump. Lateral tubercle is half turned to the ventral side, to which two large setae are seen dorsally and other 6 setae are seen from the ventral side. Ventrally, gular median setae are $3+3$, ventral tube with $3+3$ setae. Furcal rest is a rounded swelling having some 6-7 setae on it. Genital orifice is rounded in male and hemicircular in female, both with many normal setulae. Lateral flap of anus (fig. $\mathrm{H}$ ) is well separated. Median flap has only a pair of setulae, while lateral flap has 2 such setulae near the margin and with ca. 12 usual setae, whose location is to be discussed further on. Chaetal pattern has some abnormalities just as in case of Lobella sauteri (1. c.), but they are usually restricted to one side. The nearly related species of Japan, L.(Y.) pacifica Yosii, 1917 is without eyes. The species was known from Tokara Islands and now, it is found from Shikoku.

\section{Axelsonia nitida (Folsom)}

Isotoma nitida: Folsom 1899

Isotoma pteromucronata: Uchida 1965

Axelsonia nitida: Yosii 1966

Axelsonia cf. nitida: Sawada 1995

The species is typical halobiont to be found around the sea shore and known from Japan, Singapore and India (Bombay).

\section{Heterosminthurus kiianus sp.n.}

(Fig. 4)

Deuterosminthurus sp.: Sawada 1995

WAKAYAMA: Kada (1q, 1ð, 5 X 1988 Sawada.)

Body length $1.0 \mathrm{~mm}$. in $\$, 0.8 \mathrm{~mm}$ in $\delta$. Colour diffusely brownish all over. Ant.: head as 23:10 in $q$ and $30: 10$ in $\delta$. Ratio as 10:25:55:100. Ant. IV divided into 10 subsegments. Ant. III-organ is two rods in a fissure. Eyes $8+8$, intensely black. Unguis (figs. A, B) is small, triangular, with broad dorsal keel, untoothed. Unguiculus is elongated, filiform apically and with narrow basal lamella in fore- and with broad lamella in mid- and hind-legs. Each leg is with 2-3 spathulated setae, lightly cuneated basally. Ventral tube is not granulated, but with many transverse shrinking. Tenaculum is (fig. G) with tridentate rami, corpus is high, with 2 setulae apically. Furca (fig. D) in ratio as 10:35:9. Manubrium is dorsally with $8+8$ symmetrically arranged setae. Dens is with smooth setae arranged as: 


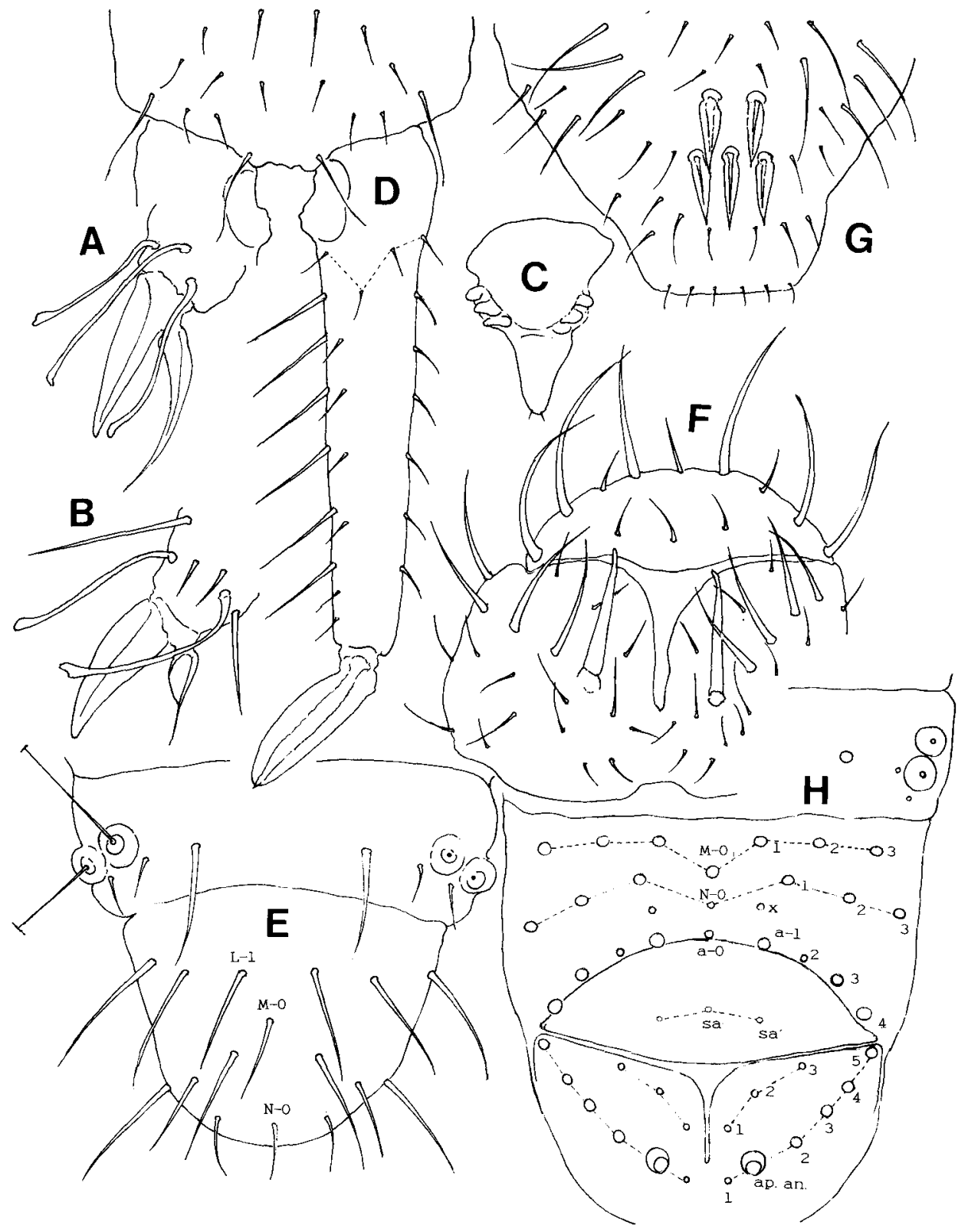

Fig. 4. Heterosminthurus kiianus sp.n. A: fore-leg, B: hind-leg, C: tenaculum, D: dens and mucro, E,F: abd. V, VI (from dorsal and ventral side), G: "nasal organ" of male, H: chaetal pattern of abd. V, VI in diagram.

proximal 4

outer lateral $1,1,1,1,1,1,1=7$

inner dorso-lateral $1,1,1,1=4$

inner lateral $1,1,1,1,1,1,1,1=8$ ( 6 longer, 2 smaller)

ventral 1 ........3,3 
Mucro is boat-shaped, both lamellae broad and not serrated. Female has abd. V distinctly separated from VI. Abd. VI is with circumanal setae as in fig. F. All body setae are slender, a little larger on posterior part of abdomen. Male is almost the same with it, but quite different having "nasal organ" just above the labral basis, in form of 5 setae arranged as 2,3. Each of them are thickly built, winged in a peculiar way, spiny apically and with broad socket at the basis. Chaetal pattern of lesser abdominal part of female is as in fig. E dorsally and as in fig. $\mathbf{F}$ ventrally. Accordingly, abd. $\mathrm{V}$ is with $2+2$ s.s., with large socket each having a long s.s. plus 2 small setae and $1+1$ macrosetae near by. Abd. VI (fig. E) has 3 transverse rows ( $\mathrm{L}, \mathrm{M}, \mathrm{N}$ ) of macrosetae including $\mathrm{M}-\mathrm{O}$ and $\mathrm{N}-\mathrm{O}$, but setae of $\mathrm{N}$ row are smaller. Upper anal lobe is with anal setae 4-1-4, where a-o and $\mathrm{a}-2$ are smaller. Lateral lobe (fig. F) has a large, smooth, lightly curving appendix analis. a-1 to $\mathrm{a}-5$ are all enlarged.

Three subanals are all small. Thus the chaetal pattern of anal lobes are almost the same with that of Ptenothrix in principle, but different in that of abd. V and VI, which are not confluent in this genus. Diagramatically, they are as in fig. $\mathrm{H}$.

The species is a near relative of $H$. nymphes Yosii, 1970, differing in the form of nasal organ, whose each seta is elongated, and broadly winged. Possibly the genus Nasosminthurus Stach, 1955 is to be included in the same category.

Conclusion: Additional material of halophilous Collembola has revealed the presence of one new genus and two new species from Japanese waters. Chaetal pattern of the head in Oudemansia has proved to belong to da Gama-scheme of 1964 and just the same with that of Neanurinae, in contrast to Brachystomella, by which the pattern is of Yosii-scheme of Hypogastruridae in 1956.

\section{Literatures}

Christiansen, K. \& P. Bellinger 1992. Insects of Hawaii, Honolulu 445 pp.

Denis, J. R. 1925. Sur la faune franc aise des Collemboles VIII. Bull. Soc. ent. Fr., 1925: 241-245.

Gama, M. M. da. 1964. Colembolos de Portugal Continental, Coimbra 1964, 252 pp.

Gama, M. M. da. 1948. Collemboles d'Indochine, Notes d'Entom. Chinoise 12: 184-311.

Schött, H. 1893. Zwei neue Collembola aus dem indischen Archipel. Entom. Tjidskr., 14: 171-176.

Uchida, H. 1955. Apterygota of Marcus Island. Bull. biogeogr. Soc. Japan, 16-19: 203-207.

Uchida, H. 1965. Collembola of the Ryukyus. Kontyu, 33: 85-96.

Uchida, H. \& Tamura, H. 1966. On three marine Collembola in Hokkaido. J. Fac. Sci. Hokkaido Univ. ser. VI, 16: 23-30.

Yosii, R. 1955. Meeresinsekten der Tokara Inseln VI: Collembolen. Publ. Seto mar. biol. Lab., 4: 379-401.

Yoshii, R. 1956. Monographie zur Hohlencollembolen Japans. Contr. biol. Lab. Kyoto Univ., no. 3,

Yoshii, R. 1966. Collembola of Himalaya. Coll. Art Sci. Chiba Univ., 4: 461-531.

Yoshii, R. 1970. On some Collembola of Japan and adjacent countries II. Contr. biol. Lab. Kyoto Univ. 23: 1-32.

Yoshii, R. 1971. Halophilous Collembola of Japan. Publ. Seto mar. biol. Lab., 18: 279-290.

Yoshii, R. 1994. On Lobella sauteri and its variability. Ann. spel. Inst. Japan, 12: 1-9. 